\title{
Numerical Analysis of Heat transfer Enhancement in a double pipe heat exchanger with a holed twisted tape
}

\author{
Akarsh Kumar ${ }^{1}$, Ujjawal Sureka $^{1}$ and Shiva Kumar ${ }^{1 *}$ \\ ${ }^{1}$ Dept of Mechanical Engineering, Manipal Institute of Technology, Manipal Acedemy of Higher \\ Education, Manipal- 576104
}

\begin{abstract}
In the present study numerical analysis of enhancement in heat transfer characteristics in a double pipe heat exchanger is studied using a holed twisted tape. The twisted tape with a constant twist ratio is inserted in a double pipe heat exchanger. Holes of diameter $1 \mathrm{~mm}, 3 \mathrm{~mm}$ and $5 \mathrm{~mm}$ were drilled at regular pitch throughout the length of the tape. Numerical modeling of a double pipe heat exchanger with the holed twisted tape was constructed considering hot fluid flowing in the inner pipe and cold fluid through the annulus.Simulation was done for varied mass flow rates of hot fluid in the turbulent condition keeping the mass flow rate of cold fluid being constant. Thermal properties like Outlet temperatures, Nusselt number, overall heat transfer coefficient, heat transfer rate and pressure drop were determined for all the cases. Results indicated that normaltwisted tape without holes performed better than the bare tube. In the tested range of mass flow rates the average Nusselt number and heat transfer rate were increased by $85 \%$ and $34 \%$ respectively. Performance of Twisted tape with holes was slightly reduced than the normal twisted tape and it deteriorated further for higher values hole diameter. Pressure drop was found to be higher for the holed twisted tape than the normal tape.
\end{abstract}

Key words: Twisted tape, Nusselt number, heat transfer rate, pressure drop

\section{Introduction}

Double pipe heat exchangers are considered to be the simple heat exchangers with the fact that they are simple in construction and easy to manufacture. The disadvantage is the length of the heat Exchanger for increased heat transfer. The process of improving the performance of heat transfer device is referred to as heat transfer enhancement technique. In the recent years high cost of the energy and material has necessitated the use of efficient heat transfer equipment. The major challenge is to make the heat transfer equipment a compact one and to achieve a high heat transfer with minimum pressure drop. Augmentation techniques in heat transfer devices reduces the thermal resistance and increase the convective heat transfer. Augmentation techniques can be classified into 3 types. Active techniques which involves some external power input for the enhancement in heat transfer. Examples include

\footnotetext{
${ }^{*}$ Corresponding author: shiva.kumar@manipal.edu
} 
mechanical aids, fluid vibration electrostatic fields, surface vibration and jet impingement [12]. Passive methods include modifications in geometry and surface to the flow channel by incorporating inserts or additional devices. They promote higher heat transfer by disturbing or altering the existing fluid flow behavior. Examples of this type includes rough surfaces, extended surfaces inserts, addition of additives etc. In the compound method combination of the above two techniques have been adapted. [3-4]. Smith Eiamsa et al. [5] experimentally studied the heat transfer characteristics in a circular pipe using normal twisted tape and also using alternate clock wise and anti-clock wise twisted tapes. Experiments were conducted in turbulent condition. They analyzed heat transfer rate and friction factor for different conditions of tapes in the turbulent regime. They observed that alternate clock wise and counter clockwise tapes were better than the normal tapes. Thianpong et al. [6] studied heat transfer characteristics using a helically coiled twisted tape. The experiments were conducted using HTTs (Helical twisted tapes) with three twist ratios (y/W) of 2, 2.5 and 3, three helical pitch ratios (p/D) of $1,1.5$ and 2. They concluded that heat transfer rate and friction factor increase as the tape twist ratio and helical pitch ratio decrease, while the thermal performance shows opposite trend. Murugesan et al. [7] carried experiments using V cut twisted tapes and compared the results with the conventional tape. At the same Reynolds number thermohydraulic performance of the V cut tapes were better than the normal tapes. Kapatkar et al. [8] carried out experimental study of using a full length twisted tape in a circular pipe under laminar flow conditions. Three different materials were chosen for the twisted tape include aluminum, stainless steel and insulated. Twist ratio of the tapes varied from 5.2 to 3.4. Twisted tapes showed higher nusselt number than smooth ones. For Aluminum tapes, the maximum improvement in Nusselt number range from 50\% to $100 \%, 40$ to $94 \%$ for stainless steel and $40-94 \%$ for insulated tape. The friction factor for the flow with the twisted tape inserts are $340 \%$ to $750 \%$ higher as compared with those of smooth tube flow. According to the author's knowledge literature regarding the holed twisted tape is scare. Hence in the present work twisted tape of uniform twist ratio with constant diameter holes throughout the length were considered for the analysis. Numerical modeling of the above geometry was done using Ansys workbench 14.5 and simulation was done with Reynolds number ranging from 2400- 6000. Heat transfer characteristics like Nusselt number, heat transfer coefficient and pressure drop were calculated. The results so obtained were compared with the results obtained by the simulation of bare tube and the tube with normal twisted tape.

\section{CFD modeling}

The geometric model of the bare double pipe heat exchanger was constructed using work bench in ANSYS 14.5 environment. Specifications selected for the bare double pipe heat exchanger are given in Table 1. The complete domain consists of 45596 Elements. Quality of the mesh was verified by performing grid independence. Initially at the inlet, temperature and mass flow rate of the cold and hot fluid were specified. At the outlet, a pressure outlet boundary is enforced. SIMPLE algorithm was used to solve pressure velocity. K-€ turbulent model was used in the analysis. For momentum turbulent kinetic energy and turbulent dissipation rate with second order upwind scheme was used. For the energy equation also second order upwind was used. Conservation equations were solved for the control volume to yield the velocity and temperature fields for the water flow in the heat exchanger. Convergence was affected when all the residuals fell below $10^{-6}$ in the computational domain. A sample residual plot for the above condition is shown in the Fig. 1. Simulations were done by changing the mass flow rates of hot fluid $(0.005,0.01 .0 .02$ and $0.03 \mathrm{~kg} / \mathrm{s})$ while mass flow rate of cold fluid being fixed at $0.01 \mathrm{~kg} / \mathrm{s}$. Heat transfer characteristics like Nusselt number, outlet temperatures were determined. Numerically simulated results were compared with analytical results calculated by using Dittus Boelter equation $N u=0.023 \operatorname{Re}^{0.8} \mathrm{Pr}^{0.33}$ for 
the above mass flow rates. The average error for Nusselt number is within $2.5 \%$ and are shown in the Fig. 2. Hence the use of CFD modeling for studying the heat transfer characteristics in a double pipe heat exchanger can be employed with confidence.

Table 1. Specifications of the numerically simulated bare double pipe heat exchanger and twisted tape

\begin{tabular}{|l|l|l|}
\hline $\begin{array}{l}\text { S. } \\
\text { No. }\end{array}$ & Specifications & Dimension $(\mathrm{mm})$ \\
\hline 1 & Inner diameter & 9.5 \\
\hline 2 & Thickness of the inner tube & 1.5 \\
\hline 3 & Inner diameter of the outer tube & 28.5 \\
\hline 4 & Thickness of the outer tube & 2 \\
\hline 5 & Length of the test section of heat exchanger & 500 \\
\hline 6 & Cross section of the twisted tape & $7 \mathrm{~mm} \times 0.7 \mathrm{~mm}$ \\
\hline 7 & Pitch of the tape & 60 \\
\hline 8 & Hole diameters in the twisted tape & 1,3 and 5 \\
\hline
\end{tabular}

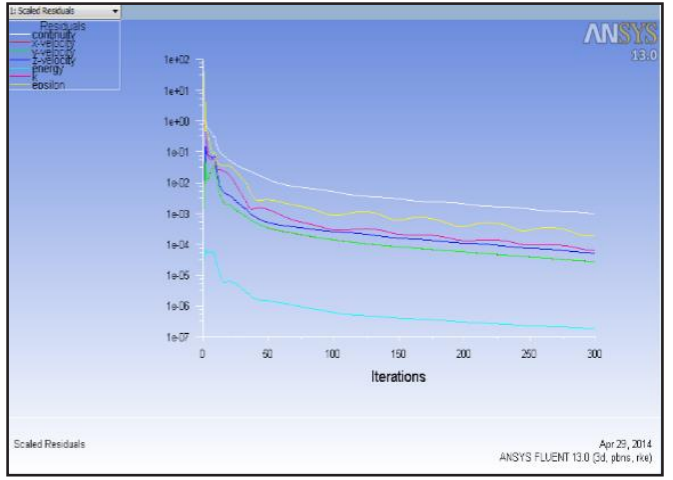

Fig. 1. Residual plot

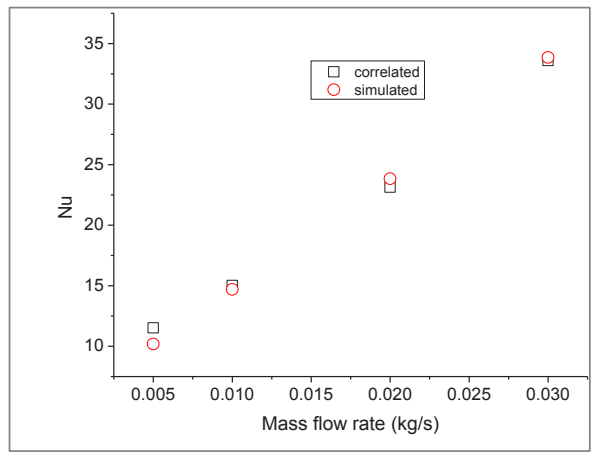

Fig. 2. Comparison of simulated and correlated values of Nusselt number for different mass flow rates of hot liquid

Geometrical modeling of the twisted tape with and without holes in a double pipe heat exchanger was constructed as shown in the Fig. 3 and 4. Specifications of the twisted tape have been mentioned in Table 1. For a holed twisted tape the holes of diameter $1 \mathrm{~mm}, 3 \mathrm{~mm}$ and $5 \mathrm{~mm}$ drilled centrally along the width of the tape. Pitch of the holes were maintained constant as that of the tape. Meshing is done by using tetrahedral elements. Numerical simulation was done for the double pipe heat exchanger using normal twisted tape, tape with holes of $1 \mathrm{~mm}, 2 \mathrm{~mm}$ and $3 \mathrm{~mm}$ respectively. Hot water inlet temperature and cold water inlet temperatures together with their mass flow rates were mentioned as the inlet boundary conditions. At the outlet Pressure boundary condition is imposed. Simulation was done for different mass flow rates of hotwater keeping mass flow rate of cold water fixed at $0.01 \mathrm{~kg} / \mathrm{s}$ as mentioned in the previous section. Outlet cold water temperature, Nusselt number and overall heat transfer coefficient and pressure drop were determined. 


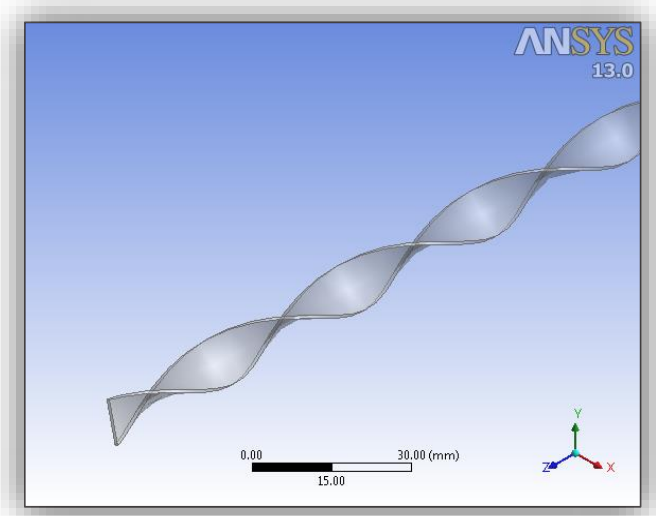

Fig. 3. A twisted tape insert

\section{Results and discussions}

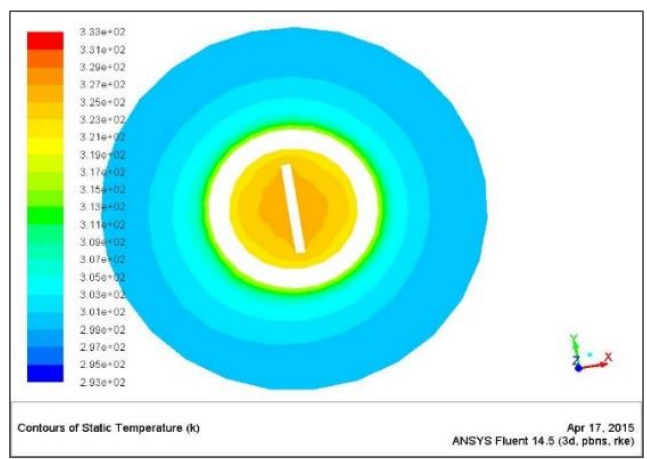

Fig. 5. Temperature profile at the outlet face of the cold water

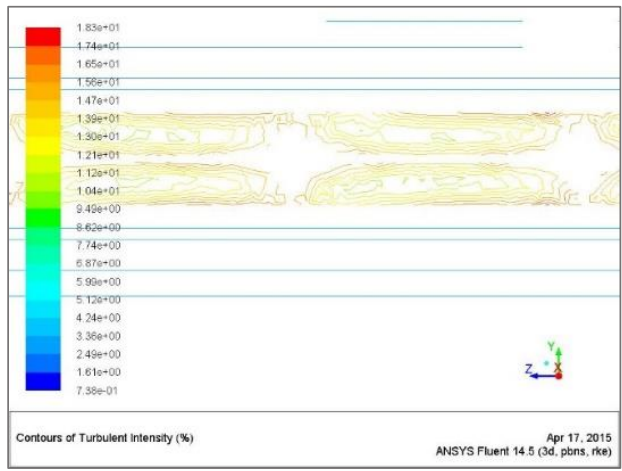

Fig. 7. Turbulent intensity plot on an iso surface in the inner tube with normal twisted tape

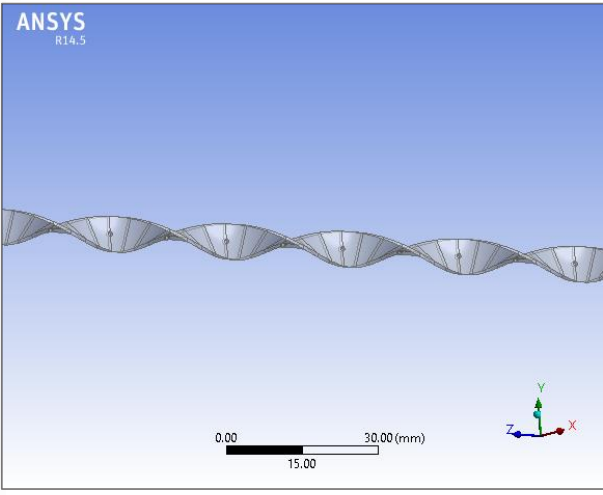

Fig. 4. A twisted tape with holes drilled centrally along the width

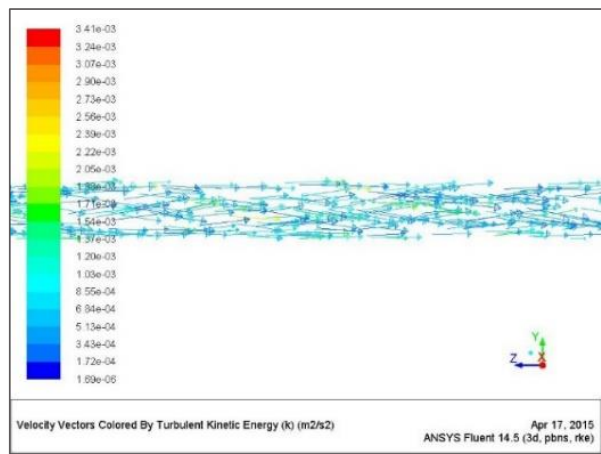

Fig. 6. Vector plot of the velocity on an iso surface showing temperature distribution near

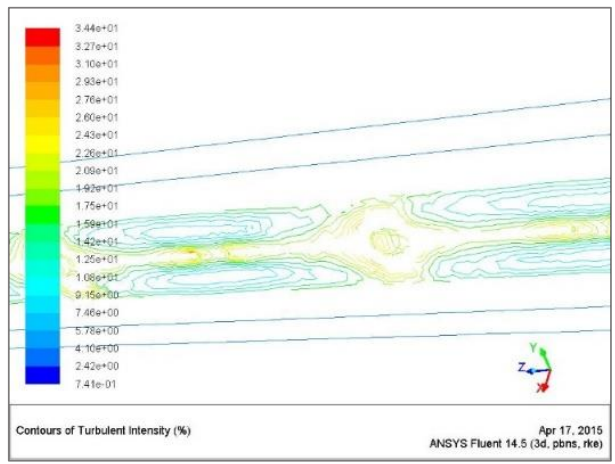

Fig. 8. Turbulent intensity plot on an iso surface in the inner tube with holed twisted tape 


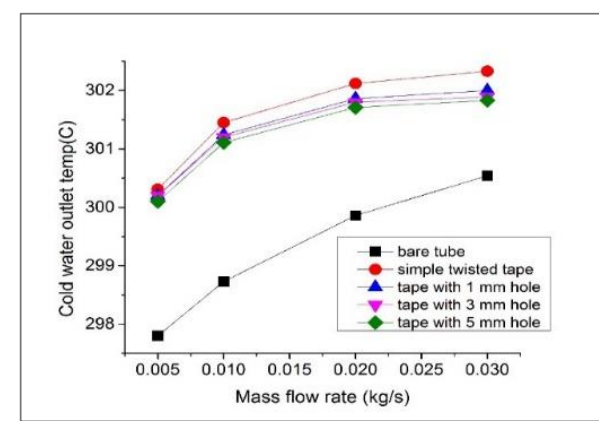

Fig. 9. Variation of cold water outlet temperature with mass flow rates of hot water for bare, twisted tape with and without holes

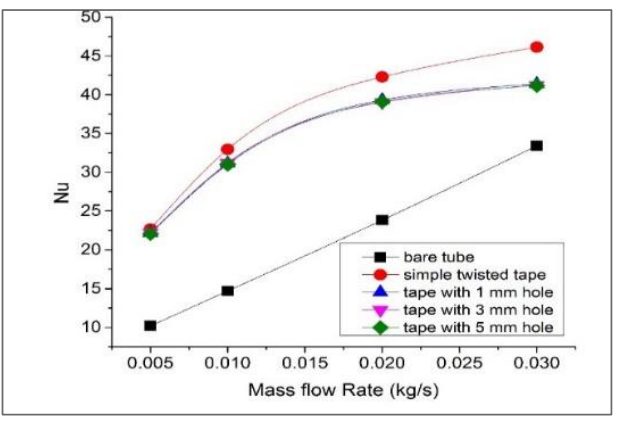

Fig. 10. Variation of Nusselt number with mass flow rates of hot water for bare, twisted tape with and without holes

Numerical simulation reveals that average Cold water outlet temperature is found to be increasing with mass flow rates and is higher for twisted tape than the bare tube. Fig. 5 represents the temperature distribution plot on the cold water outlet face for tube with a twisted tape for a mass flow rate of $0.01 \mathrm{~kg} / \mathrm{sec}$ for both cold and hot water. Since the geometry of the twisted tape continuously changes this introduces swirl into the bulk flow there by disrupting the boundary layer at the surface. It induces turbulence and superimposed vortex motion causes the higher heat transfer rate. The velocity plot and turbulence plot for the normal twisted tape are shown in Fig. 6 and 7 respectively. Fig. 8 represents the turbulence plot for the twisted tape with holes. For the holed twisted tapeslight increase in turbulence than the normal tape is insufficient to overcome heat conduction that would have been taken place from the region of holes in case of normal twisted tape. This may led to little reduced performance and hence reduced outlet temperature than the normal tape.

Fig. 9 shows the comparison of variation of outlet temperature of the cold water with mass flow rates of bare pipe, pipe with twisted tape and twisted tape with holes under turbulent conditions. It is observed that the average outlet temperature of the cold water is least for bare tube on comparing it with different cases. In case of tube with twisted tape the turbulence induced in the flow path reduces the boundary layer thickness and hence increases the heat transfer with increasing the cold water outlet temperature. The average outlet temperature for a twisted tape is $90 \%$ higher than the bare tape under tested conditions. For increased mass flow rates this difference between putting a limit on the Reynolds number for better performance using a twisted tape as is clear from the Fig. 9. For holed twisted tape the outlet temperature was found to be less than the tube with twisted tape for all mass flow rates. On comparing the outlet temperature for the different hole diameters, it was observed outlet temperature drops marginally on increasing the hole diameters. For higher diameters less swirling action which results in reduced turbulence and hence reduced heat transfer rate which resulted in reduced outlet temperatures.

Fig. 10 shows the variation of Nusselt number with mass flow rate for the five cases. Nusselt number was found to increasing with mass flow rates for all the cases. For the bare tube it is found to be lesser than the tube with the twisted tape as well as with holes. For a twisted tape insert the effective hydraulic diameter reduces which alternatively increases the fluid velocity. This in together with the swirling motion increases the Reynold's number and hence Nusselt number. For a holed tube case it is found to be lesser than the normal twisted tube showing its deteriorated performance when compared with the former. As the hole diameter was increased the Nusselt number values decreased marginally showing the poor performance with large diameter holes. It was found that the average Nusselt number increased by $85 \%$ for twisted tape than the bare tube. 


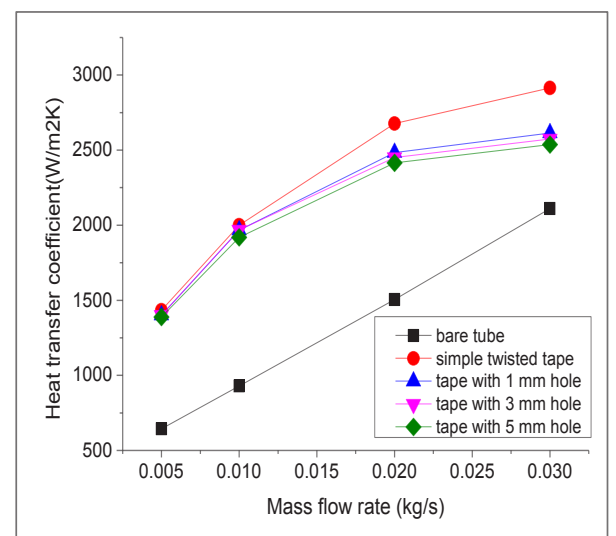

Fig. 11. Variation of heat transfer coefficient with mass flow rates of hot water for bare, twisted tape with and without holes

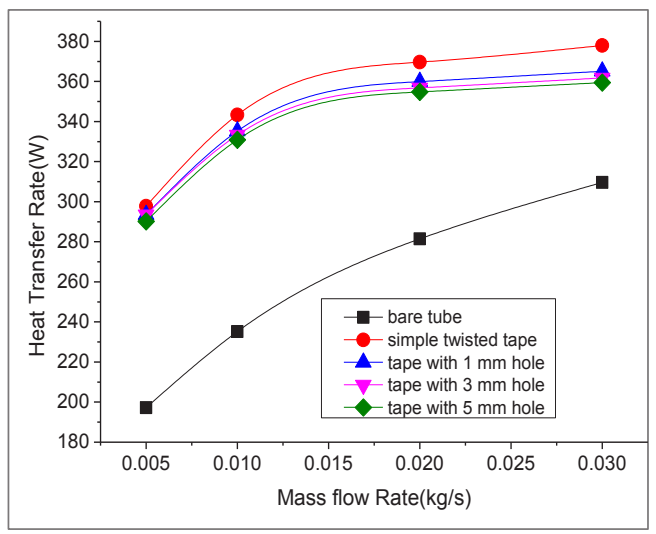

Fig. 12. Variation of heat transfer rate with mass flow rates of hot water for bare, twisted tape with and without holes

Fig. 11 shows the plot of heat transfer coefficient for the different cases. It was again observed that it increases with the mass flow rates of hot fluid. Heat transfer coefficient for the bare tube will be found to be lower than the twisted tape with and without holes. Disturbance in the flow field by introducing a twisted tape will disturb the boundary layer at the tube surface and hence increases the heat transfer coefficient. For a holed twisted tape heat transfer coefficients were found to be marginally lesser than the normal as discussed in the earlier section. This reduces the net heat transfer coefficient slightly for the holed twisted tape. As the hole diameter increases this trend continues further reducing the heat transfer coefficient due to reduced turbulence for higher diameter holes as seen clearly in Fig. 11. For the twisted tape the average heat transfer coefficient has increased by $82 \%$ compared with the bare tape.

Fig. 12 shows the heat transfer rates for the different tested cases. It increases with the introduction of the twisted tape into the double pipe heat exchanger for all tested mass flow conditions. The average heat transfer rate is increased by $34 \%$ compared to the bare tube. Gain in heat transfer rate decreases for the increased Reynolds number as seen in Fig. 12. For higher mass flow rates primary velocity will be increased and hence swirl flow will be reduced which hence flow boundary will not be affected much. The heat transfer rate for a holed tape is lower due to the reason that increase in the turbulence is not able to overcome the conduction losses. Hence the average heat transfer rate decreases. With respect to different hole diameters there was not much appreciable change in the heat transfer rate showing drilling a single hole in a twisted tape will not influence much heat transfer characteristics in a double pipe heat exchanger.

Fig. 13 shows the variation of the pressure drop for bare, twisted tape with and without holes. Pressure drop for the twisted tape is higher than the bare tube for all tested mass flow rate conditions. It is still higher for holed tape. For a definite configuration it is observed that it increases with mass flow rates. For a normal twisted tape the average pressure drop is 2.85 times than the bare tube. Similarly for the holed twisted tape they are 8.7\%, 9.1\% and $10.02 \%$ for $1 \mathrm{~mm}, 3 \mathrm{~mm}$ and $5 \mathrm{~mm}$ holes respectively higher than the normal twisted tape. Increase in pressure drop increases the pumping power. For a holed tape thermal performance decreases in addition to increase in the Pumping power. Hence drilling a single hole along the width of a twisted tape will be least effective in increasing the thermal performance of a twisted tape. 


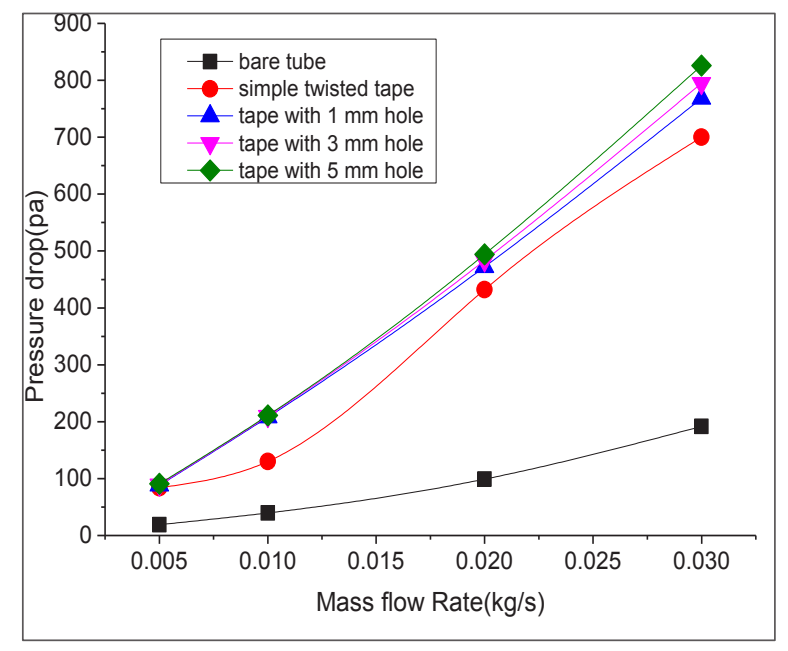

Fig. 13. Variation of pressure drop with mass flow rates of hot water for bare, twisted tape with and without holes

\section{Conclusions}

In the present study thermal performance of a twisted tape with and without holes in a double pipe heat exchanger was studied numerically. Along the length of the tape diameters of 1 $\mathrm{mm}, 2 \mathrm{~mm}$ and $3 \mathrm{~mm}$ were drilled. Performance parameters like nusselt number, heat transfer coefficient and pressure drop were measured and were compared with the bare tube. For a twisted tape Nusselt number, heat transfer coefficient were found to be higher and pressure drop also increased. In case of holed tape Nusselt number and heat transfer coefficient were decreased slightly with respect to normal twisted tape with the increase in pressure drop. Hence it can be concluded that drilling a single hole at regular pitch along the length will not be that effective in increasing turbulence and hence the thermal performance of the tape. Instead of that a large number of small diameter holes can be drilled at a regular pitch to induce more swirl in the flow path which may influence thermal characteristics effectively.

\section{References}

1. Chintan Prajapati, Pragna Patel, Jatin Patel3and Umang Patel, Review of heat transfer enhancement using twisted tape, International Journal of Advanced Engineering Research and Studies, Vol ii/Issue I, 2012, pp-162-164.

2. S. Tabatabaeikia, H. A. Mohammed, N. Nik-Ghazali, and B. Shahizare1, Heat Transfer Enhancement by Using Different Types of Inserts, Advances in Mechanical Engineering, Volume 2014, Article ID 250354,

3. S. Pal, S.K. Saha, Laminar flow and heat transfer through a circular tube having integral transverse corrugations and fitted with centre-cleared twisted-tape, Experimental Thermal and Fluid Science, vol. 57, 2014, pp. 388-395.

4. S.W. Chang, M.H. Guo, Thermal performances of enhanced smooth and spiky twisted tapes for laminar and turbulent tubular flows, International Journal of Heat and Mass Transfer, vol. 55, Issue 25-26, 2012, pp. 7651-7667,.

5. Smith Eiamsa-ard a, Pongjetn Promvonge, Performance assessment in a heat exchanger tube with alternate clockwise and counter-clockwise twisted-tape inserts, International Journal of Heat and Mass Transfer, 53, 2010, pp.1364-1372. 
6. Eiamsa-ard, K. Yongsiri, K. Nanan, C. Thianpong, Heat transfer augmentation by helically twisted tapes as swirl and turbulence promoters, Chemical Engineering and Processing: Process Intensification, Elsevier, vol. 60, 2012, pp. 42-48,

7. P. Murugesan,a , K. Mayilsamyb, S. Suresh, Heat Transfer and Friction Factor in a Tube Equipped with U-cut Twisted Tape Insert, Jordan Journal of Mechanical and Industrial EngineeringVolume 5, Number 6, 2011.

8. A. V. N. Kapatkar , B. Dr. A. S. Padalkar and C. Sanjay Kasbe, Experimental Investigation on Heat Transfer Enhancement in Laminar Flow in Circular Tube Equipped with Different Inserts, International Journal on Manufacturing and Material Science, Vol. 01, No. 01, 2011. 